Review article

Paediatrics Today 2016;12(1):56-65

DOI $10.5457 / \mathrm{p} 2005-114.136$

\title{
CONTRAST-ENHANCED VOIDING UROSONOGRAPHY (ceVUS) AS A DIAGNOSTIC TOOL IN EVALUATION OF VESICOURETERAL REFLUX
}

\author{
Andrea CVITKOVIĆ ROIĆ ${ }^{*}$, Goran ROIĆ², Iva PALČIĆ ${ }^{1}$, Alemka JAKLIN KEKEZ1 \\ ${ }^{1}$ Polyclinic for Pediatric Diseases \\ Helena, Zagreb, Croatia, ${ }^{2}$ Children's \\ Hospital Zagreb, Zagreb, Croatia \\ *Corresponding author: \\ andreack@workmail.com \\ Tel.: 38512310067 \\ Fax.: 3851231019 \\ Received: November 12, 2015 \\ Accepted: January 22, 2016 \\ Key words: Contrast enhanced voiding \\ urosonography - Vesicoureteral reflux • \\ Children.

\begin{abstract}
The aim of this paper is to show the benefits of contrast-enhanced voiding urosonography as a new method in the diagnosis of vesicoureteral reflux. In the era of increasing radiation awareness, radiation doses to infants and children should be kept as low as reasonably achievable. Recent advances in tissue-harmonic and contrast-specific imaging techniques, together with the development of second-generation contrast agents, have improved the potential of ultrasonography, in both the diagnosis and grading of vesicoureteral reflux in children. Contrast-enhanced voiding urosonography is a radiation free, reliable, highly sensitive and safe imaging modality for vesicoureteral reflux and urethral evaluation in children. Conclusion - Therefore, due to all its advantages, contrast-enhanced voiding urosonography is the preferred method in the diagnosis and grading of vesicoureteral reflux and should be incorporated into the paediatric urinary tract infection
\end{abstract} \\ diagnostic algorithm.
}

\section{Introduction}

Vesicoureteral reflux (VUR) is one of the most common urinary tract anomalies in children and may be associated with reflux nephropathy (RN). Some patients with $\mathrm{RN}$ develop chronic kidney disease, hypertension and a small number of patients progress to end-stage renal disease (1). Early detection of children with these clinical characteristics should be the goal of evaluation of patients presenting with prenatal hydronephrosis or febrile urinary tract infection (UTI). The goals of the imaging procedure in general are to confirm the suspected diagnosis, with a high degree of sensitivity and specificity, to aid treatment and allow prognosis.

VUR is not only a developmental anomaly related to the inadequate length of the intravesical submucosal ureter, but also a dysfunctional problem, in relation to which many patients have associated neurogenic and non-neurogenic bladder and bowel dysfunction $(2,3)$. VUR is associated with RN and renal scarring, which can cause hypertension and renal failure. Today, controversies exist about the role of VUR in the development of UTI, as well as the effectiveness of antibiotic prophylaxis in preventing pyelonephritis and scarring (4-6). Nonetheless, it is recommended to exclude VUR in high-risk patients, including those with hydronephrosis, renal scarring, with an atypical UTI or complex clinical circumstances, especially in children with neurogenic and non-neurogenic bladder and bowel dysfunctions $(5,7)$.

The purpose of this review is to demonstrate the advantages, as well as the limitations of contrast-enhanced voiding urosonography 
(ceVUS), compared to other standard techniques in diagnosing VUR.

\section{Diagnostic methods for vesicoureteral reflux identification}

Three methods are currently used to identify VUR in children: (1) radiographic voiding cystourethrography (VCUG), (2) direct radionuclide cystography (DRNC) and, more recently, (3) contrast-enhanced voiding urosonography (ceVUS).

\section{Radiographic voiding cystourethrography}

Voiding cystourethrography (VCUG) has been the gold standard of imaging for diagnosing and grading of VUR. It is a fluoroscopic examination, utilizing radiographic contrast medium and fluoroscopic (X-ray) screening. The procedure involves bladder catheterization and intravesical administration of radiographic contrast via a urinary catheter, followed by continuous fluoroscopic examination of the lower abdomen and pelvis. The presence of the radiographic contrast in the upper urinary tract during bladder filling and voiding is diagnostic of VUR. A standardized international system is used for reflux grading (8). This method involves exposure to ionizing radiation. The standard mean effective dose of VCUG is approximately 0.4 to $0.9 \mathrm{mSv}$ (9). Patient dose reduction during VCUG can be achieved using pulsed fluoroscopy. With this new modality the radiation exposure is at least eight times lower than that delivered by conventional continuous fluoroscopy $(10,11)$. This is especially important in children who are more susceptible than adults to the long-term hazards of radiation. Developing tissue in children is more sensitive to the effects of radiation and children have a longer life expectancy during which the potentially oncogenic effects of radiation may be manifested (12). Also, as VUR is an intermittent phenomenon, it can sometimes be missed by intermittent fluoroscopic screening techniques. The dilution of a small amount of radiographic contrast in the already-dilated collecting system, and obscuration by overlying bowel shadow, also contribute to the lower sensitivity of VCUG (13).

\section{Direct radionuclide cystography}

Direct radionuclide cystography (DRNC) also involves bladder catheterization and intravesical administration of radiopharmaceuticals. The advantages of this method are the continuous examination of the kidneys and bladder during the filling phase, and the lower gonadal radiation dose. In general, it has comparable diagnostic performance with VCUG, but lower spatial resolution and impaired anatomical delineation. It is usually recommended for follow up of VUR, particularly in boys, due to its limited efficacy in examining the urethra (14).

\section{Contrast-enhanced voiding urosonography}

Contrast-enhanced voiding urosonography (ceVUS) is a new technique in the evaluation of VUR. The second generation of ultrasound contrast agents (UCA) and higher quality ultrasound machines, with contrast-specific software technology, have allowed the application of ceVUS without ionizing radiation (15). ceVUS has become a routine method in the diagnosis of VUR in many European centres, because in recent years there is higher awareness of the potential harmful effects of exposure to ionizing radiation in diagnostic imaging procedures in children (15-23). Kis et al. (25) reported ceVUS to be more sensitive than VCUG since it is a real time imaging method, allowing prolonged, continuous scanning, and thus has the potential to detect 
intermittent VUR (24). It can be repeated without exposure to radiation if the procedure fails. It also allows adequate imaging of the urethra (26-29).

The first attempts at implementation of ultrasound (US) for diagnosis of VUR began in the mid-1970s. A comprehensive account of the evolution of this undertaking over the subsequent two decades has been presented by Darge (22)who presented various attempts that were undertaken in the past to introduce ultrasonography for diagnosis of VUR, the limitations of indirect methods and the revolution that occurred with the availability of stable UCA.

Diagnostic imaging is now a practical option for examination of VUR, is relatively easy to perform using new and stable UCAs. The intravesical use of a sonicated albumin UCA (Albunex; Molecular Biosystems, San Diego, Calif.) for VUS in a child was first reported in 1994 (30). Another UCA used in the past was Echovist (Schering, Berlin, Germany), which is composed of galactose with incorporated microbubbles (31). It has a very short imaging window of approximately only $5 \mathrm{~min}$, which, thus, prevents its routine application. A breakthrough in US diagnosis of VUR in children evolved during the mid-1990s with the availability of UCAs containing stabilized microbubbles. Levovist (Levograf, Schering Spain, Madrid, Spain; SHU-508-A, Schering, Berlin, Germany) was the first such UCA to become available for clinical use in Europe. This was the beginning of the rapid development of VUS and its introduction as part of the routine diagnostic imaging option for VUR (32-34) (Fig. 1). The diagnostic performance of ceVUS has further improved since the introduction of the more stabilized second generation UCA for intravesical application, as well as advances in ultrasound techniques, namely, harmonic imaging $(35,36)$. Second-generation UCAs, such as SonoVue (SonoVue, Bracco, Italy), have several intrinsic advantages (37). SonoVue is a stable aqueous suspension of sulphur hexafluoride microbubbles, with a phospholipid shell, which resonates by asymmetric contraction and expansion, and it strongly increases the ultrasound backscatter, allowing visualization. It remains stable for up to 6 hours. The procedure also involves tissue harmonic imaging, which is based on
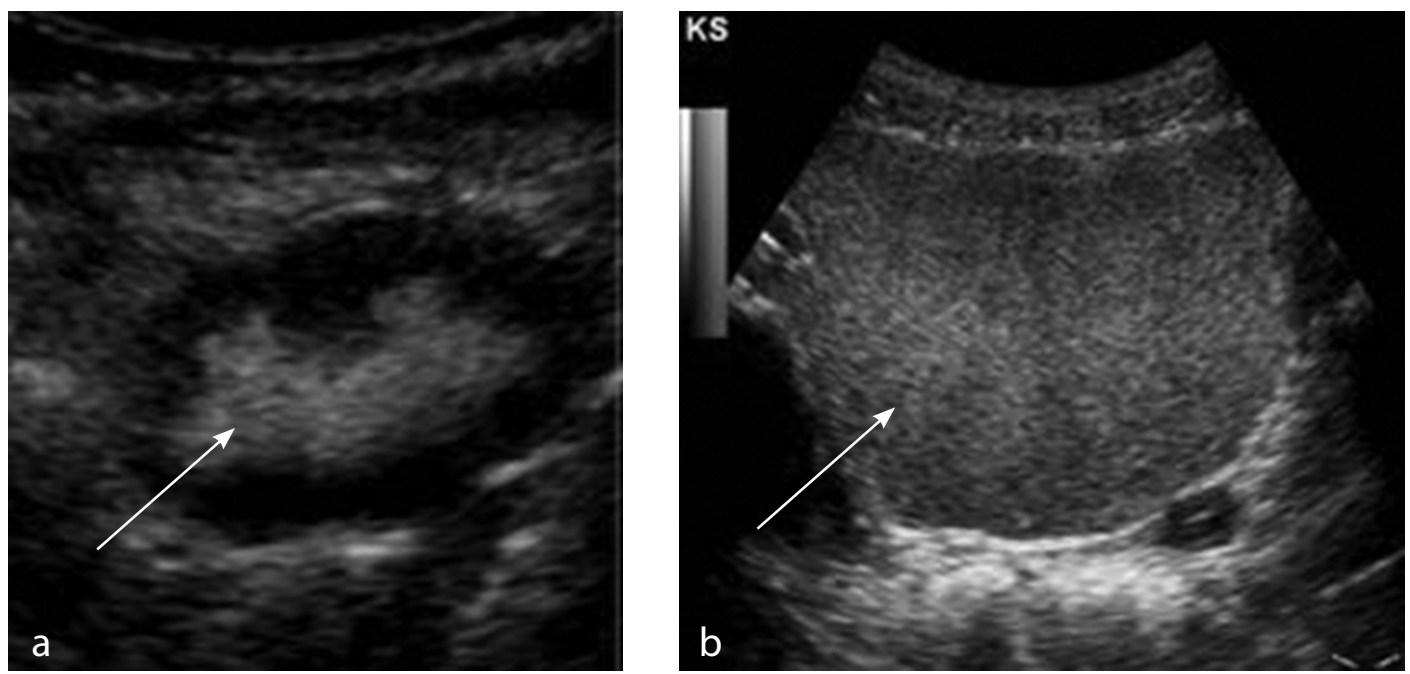

Fig. 1 Voiding contrast cystography with contrast enhanced voiding urosonography. Visualisation of the ultrasound contrast medium during voiding contrast cystography in B-mod "grayscale". a) contrast in the kidney collecting system, b) contrast in the bladder. 
the phenomenon of non-linear distortion of the acoustic signal as the ultrasound wave insonates and travels through the body tissues. It improves contrast and spatial resolution, and reduces artefacts when compared to conventional grayscale ultrasound $(38,39)$. Together with the subtraction technique, the contrast-specific harmonic imaging mode further increases the conspicuity of the microbubbles. With the application of newergeneration UCA and ultrasound techniques, ceVUS is currently regarded in Europe as a valid, radiation-free imaging modality for examination of VUR.

The procedure is technically analogous to conventional VCUG. The UCA is administered intravesically via a urinary catheter, followed by continuous, alternate examination of the kidneys, urinary bladder, and the retrovesical region during filling and voiding phases, as well as the urethra, by means of the transperineal or interscrotal approach during the voiding phase. The diagnosis of VUR is determined by the presence of moving echogenic microbubbles from the ultrasound contrast in the upper urinary tract. The fivetier grading system developed by Darge and Troeger (40) is similar to the international reflux system: Grade I Microbubbles only in the ureter; Grade II Microbubbles in the renal pelvis; no significant renal pelvic dilatation; Grade III Microbubbles in the renal pelvis + significant renal pelvic dilatation + moderate calyceal dilatation; Grade IV Microbubbles in the renal pelvis + significant renal pelvic dilatation + significant calyceal dilatation; Grade V Microbubbles in the renal pelvis + significant renal pelvic dilatation and calyceal dilatation + loss of renal pelvis contour + dilated tortuous ureters.

The utilization of stable UCAs has revolutionized ultrasound-based reflux imaging, by enabling prolonged sonographic examination of the upper urinary tract. Darge (41) showed the diagnostic performance of ce-
VUS using the first-generation ultrasound contrast Levovist. Using VCUG as the reference method, the sensitivity of ceVUS ranged from 57 to $100 \%$, and its specificity from 85 to $100 \%$. The diagnostic accuracy, measuring the concordance of both positive and negative cases, ranged from 78 to $96 \%$. Approximately $10 \%$ of all reflux units were diagnosed by VCUG alone, and $9 \%$ were diagnosed by ceVUS alone. However, the majority of reflux units missed on ceVUS were of low grade, while most missed refluxes on VCUG were of medium-to-high grade. The intermittent nature of VUR, together with intermittent fluoroscopy, and dilution of the radiographic contrast were postulated to result in a lower detection rate of high-grade reflux on VCUG. On the other hand, the lower detection rate of low-grade reflux on ceVUS was attributed to the difficulty in visualizing the retrovesical regions and the non-dilated ureter, related to the acoustic shadow cast by the intravesical contrast (41). Currently, secondgeneration contrast SonoVue-enhanced VUS has superior sensitivity, ranging from 80 to $100 \%$, and specificity of 77 to $97 \%(19,20$, 24, 37, 38, 39, 41). Moreover, SonoVue-enhanced VUS has a consistently higher reflux detection rate than VCUG. Data show that VCUG misses 6 to $62 \%$ of all reflux units. In the study by Ključevšek et al. (20) 26 (62\%) out of 42 reflux units were additionally identified by ceVUS alone, but none by VCUG alone. On the other hand, ceVUS misses only 0 to $12 \%$ of all reflux units $(19,20,24$, $38,39)$. Therefore, ceVUS is not only highly concordant with VCUG for reflux detection, but also more sensitive than VCUG.

Studies have shown that with harmonic imaging and modified US techniques, ceVUS has good reliability in diagnosing VUR in children, but requires highly skilled sonographers (42). The dosage of SonoVue for each ceVUS examination is about $0.5 \%$ of bladder capacity for age, which is adequate 
for 2-3 cycles of filling and voiding phases. Therefore, a vial of SonoVue can be shared between several patients at each session (20).

Adverse events with this method are extremely rare. In a recent European survey, there were no allergic reactions or adverse events related to SonoVue in 5079 paediatric ceVUS examinations performed in 45 European centres (43). Only a few minor adverse events related to catheterization were encountered. In our institution, we have been using ceVUS in VUR diagnosis for 10 years. We can also confirm the high safety profile of SonoVue-enhanced VUS. No adverse events related to the contrast agent, catheterization, or infection have been noticed. During the ceVUS procedure, we first perform baseline US in the prone position to assess renal size, parenchymal echogenicity and pelvicaliceal dilatation and then in the supine position for visualisation dilated ureters in the retrovesical space.

Using a $20 \mathrm{ml}$ syringe, saline is slowly instilled into the bladder via the urethral catheter, while the child is in the supine position, until the bladder volume reaches the estimated age-related maximum. This is estimated using the following equation: Bladder capacity volume $(\mathrm{ml})=$ [age (years) $\mathrm{x} 30]+$ $30 \mathrm{ml}$ (44). Then SonoVue is diluted into a
$5 \mathrm{ml}$ solution. A total of $2.5 \mathrm{ml}$ of the SonoVue solution is administered into the salinefilled urinary bladder. The bladder, ureters and kidneys are scanned alternatively during continued filling, voiding, and after voiding in the supine position. The child is also examined in a prone position. Transabdominal and transperineal scanning of the urethra is performed throughout. The diagnosis and grading of VUR is determined by the presence of echogenic microbubbles from the ultrasound contrast in the upper urinary tract (40). In newborns and infants, who tend to void before maximum filling bladder capacity is reached, ceVUS examination is repeated in a cyclical manner, with performance of successive cycles of bladder filling after voiding, until ceVUS examination is appropriately completed. A contrast-specific mode with a low mechanical index of 0.08-0.12 and high-resolution ultrasound is used. The ceVUS study is digitally recorded and stored on a hard drive. It is obtained in all cases and available for review (19) (Fig. 2-6).

Most clinical indications of VCUG may be performed by ceVUS. ceVUS were incorporated into the joint guidelines for urological examination of the European Society of Urogenital Radiology (ESUR) and the European Society of Paediatric Radiology (ESPR)

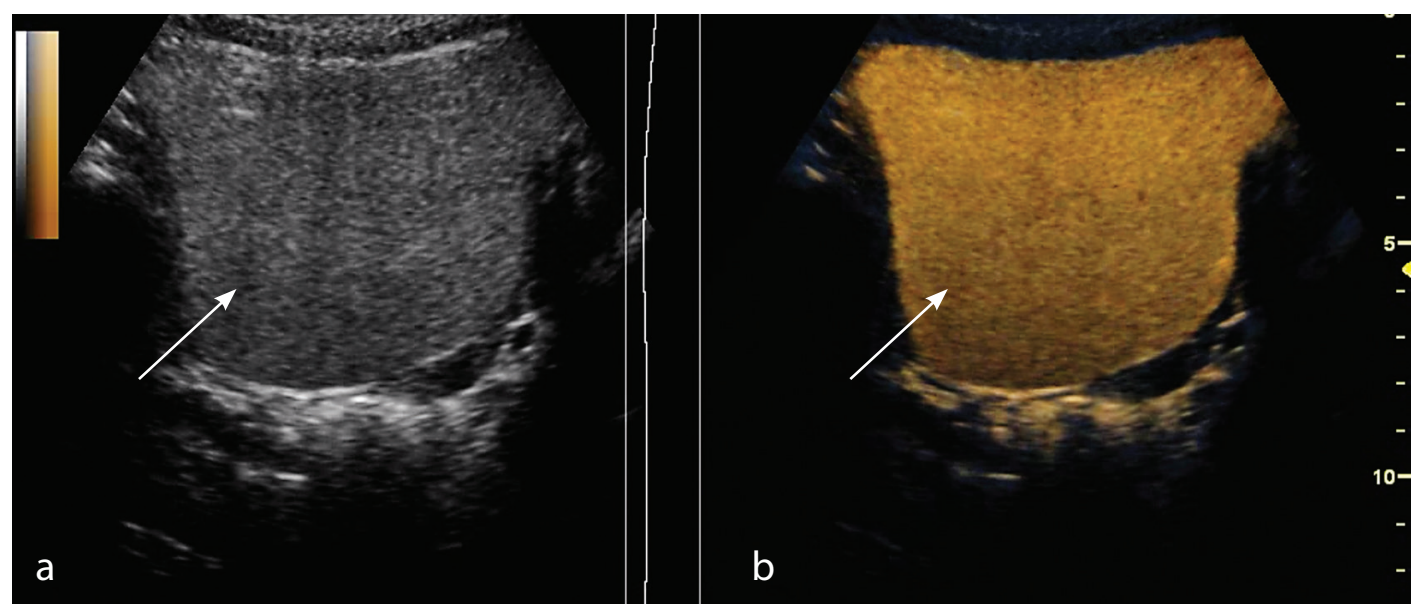

Fig. 2 Voiding contrast cystography with contrast enhanced voiding urosonography. Bladder filled with ultrasound contrast medium. a) B-mod "grayscale", b) B-mod + colour coding contrast (contrast specific software). 


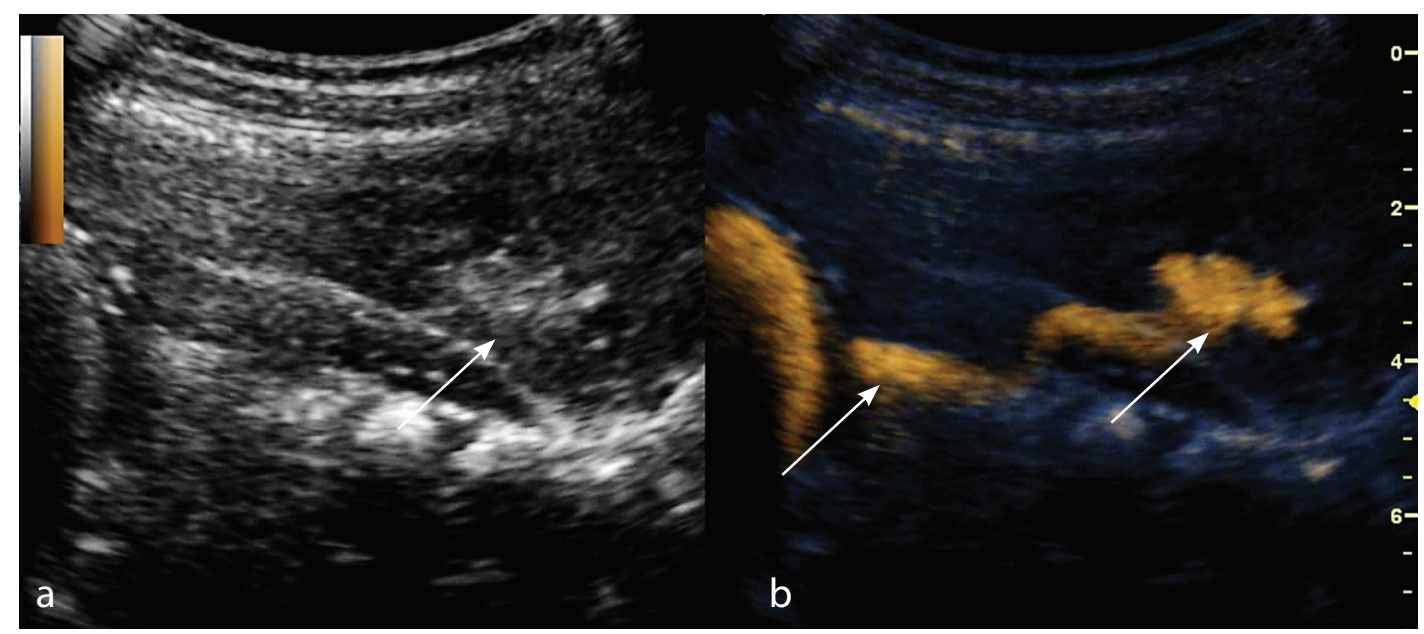

Fig. 3 Voiding contrast cystography with contrast enhanced voiding urosonography. Reflux of the contrast medium into the ureter and kidney collecting system. Contrast specific software facilitates the visibility of the colour coded contrast medium in the ureter and kidney collecting system. a) "grayscale", b) "grayscale" + contrast specific software.

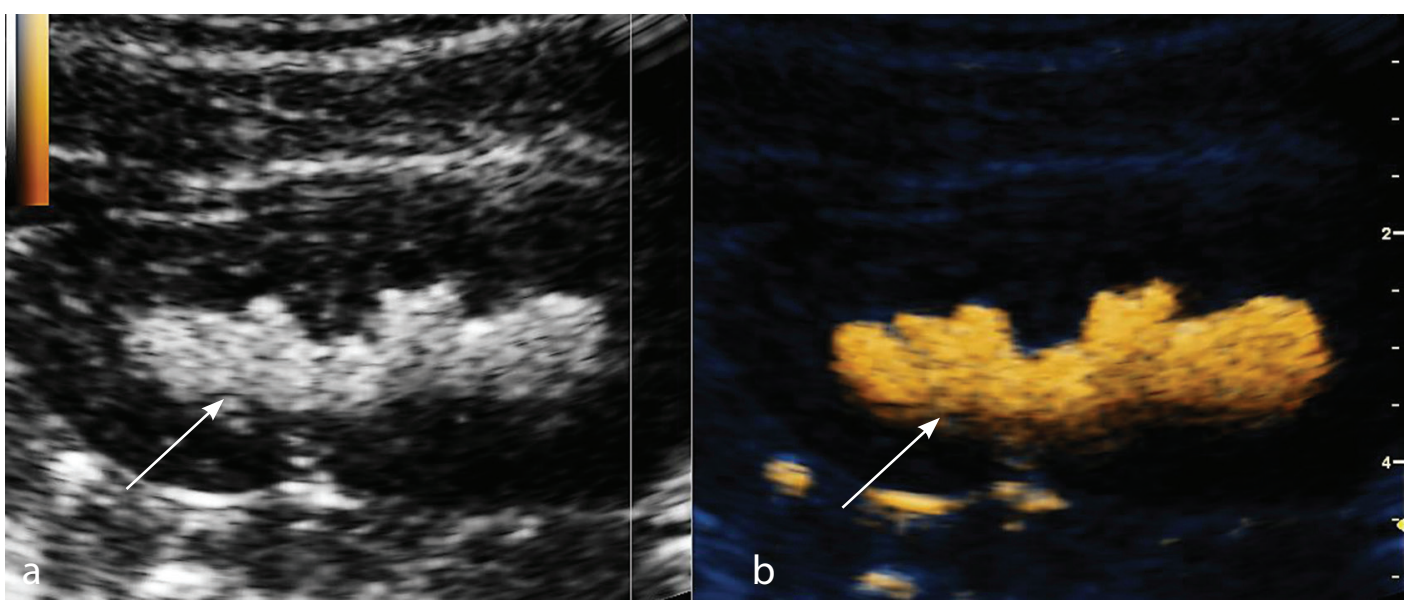

Fig. 4 Voiding contrast cystography with contrast enhanced voiding urosonography. Reflux of the contrast medium into the kidney collecting system; Contrast specific software allows colour coding of the ultrasound contrast medium and significantly increases the visibility of the contrast medium in the kidney collecting system. a) $B$ mod "grayscale", b) B-mod + contrast specific software.

in 2007 (45). The indications for ceVUS first included follow-up examination of known VUR, investigation of UTI in girls, as well as screening for familial history of VUR and foetal hydronephrosis. In recent years, ceVUS has also allowed adequate imaging of the urethra (26-29). Duran et al. (46) revealed that diagnosis of urethral pathologies, such as posterior urethral valve, prostatic utricle diverticulum, and anterior urethral stricture may be achieved by using interscrotal and transperineal approaches in boys (46). The application of ceVUS has been extended to investigation of UTIs in boys and urethral imaging in genitograms in the ESUR and ESPR guidelines 2012 (47). The main limitation of ceVUS is the acoustic shadowing produced by the high concentration of 
ultrasound contrast, which can sometimes obscure the retrovesical region and, thus, decrease the sensitivity of ceVUS in detecting a grade I reflux. This is remedied by dilution of the ultrasound contrast by continuous saline infusion, and is best assessed during the second cyclical examination. In addition, ceVUS has limitations in examinations that require detailed anatomical assessment, such as in the evaluation of fistula in children with anorectal malformation, or in detailed bladder neck evaluation (41).

We should also mention that SonoVue, although it is commonly used for diagnosis of VUR in children, has not been registered for use in patients below the age of 18 years $(43,47)$. Its use is off-label and the lack of registration for use in paediatric patients is associated with the lack of clinical trials. Appropriate trials, allowing for the official legalization and registration of such agents

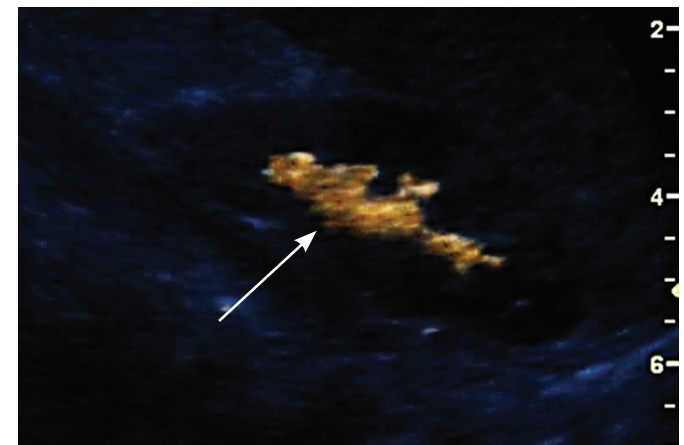

Fig. 5 Voiding contrast cystography with contrast enhanced voiding urosonography. Visualisation of the ultrasound contrast medium in the collecting system of the kidney using contrast specific software ("only contrast").

in paediatric patients, should be conducted (47). Despite the fact that SonoVue is not registered for use in patients below the age of 18 , there are numerous reports worldwide describing ceVUS in paediatric patients with intravesical administration. $(20,24,39,45)$.

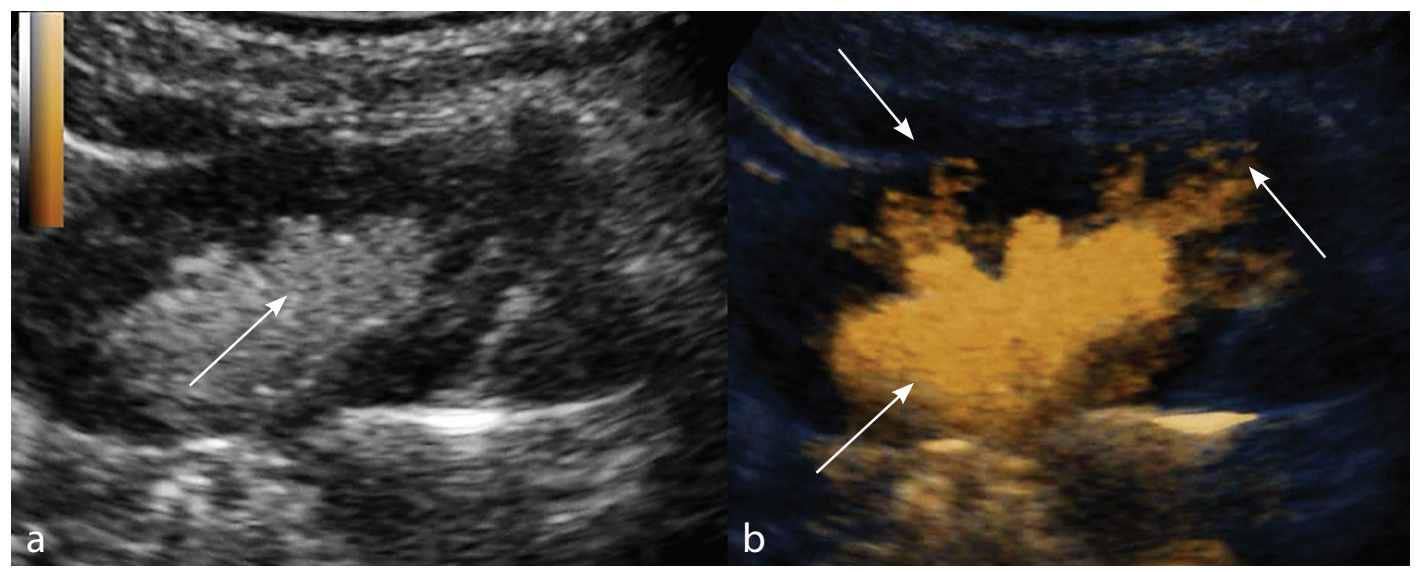

Fig. 6 Voiding contrast cystography with contrast enhanced voiding urosonography. Intrarenal reflux Visualisation of the ultrasound contrast medium in the collecting system of the kidney using contrast specific software.

\section{Conclusion}

There is increasing awareness of the risks of radiation exposure and invasiveness of VUR investigation. Currently, contrast-enhanced voiding urosonography (ceVUS) is a radiation free, sensitive, reliable and safe imaging modality for vesicoureteral reflux and ure- thral imaging in children. It employs ultrasound technology (contrast-specific software) in combination with a commercially available second generation ultrasound contrast. Due to all its advantages, of which high sensitivity, high specificity and no radiation are the most pronounced, ceVUS has the poten- 
tial to greatly reduce the use of VCUG in specialized centres.

Authors' contributions: Conception and design: ACR, GR, IP, AJK; Acquisition, analysis and interpretation of data: ACR, GR, IP, AJ; Drafting the article: ACR, IP, GR, AJK; Revising it critically for important intellectual content: ACR, IP, GR, AJK.

Conflict of interest: The authors declare that they have no conflict of interest.

\section{References}

1. Sjöström S, Jodal U, Sixt R, Bachelard M, Sillén U. Longitudinal Development of Renal Damage and Renal Function in Infants With High Grade Vesicoureteral Reflux. J Urol. 2009;181(5):2277-83.

2. Gargollo PC, Diamond DA. What nephrologist need to know about primary vesicoureteral reflux. Nat Clin Pract Nephrol. 2007; 3(10):551-63.

3. Farhat W.A, Nguyen H.T. The Changing Concepts of Vesicoureteral Reflux in Children. Adv Urol. 2008; 2008:767138.

4. Pennesi M, Travan L, Peratoner L, Andrea B, Adriano C, Luca R, et al. North East Italy Prophylaxis in VUR study group. Is antibiotics prophylaxis in children with vesicoureteral reflux effective in preventing pyelonephritis and renal scars? A randomized, controlled trial. Pediatrics. 2008;21:e1489-94.

5. Subcommittee on Urinary Tract Infection, Steering Committee on Quality Improvement and Management, Roberts KB. Urinary tract infection: clinical practice guideline for the diagnosis and management of the initial UTI in febrile infants and children 2 to 24 months. Pediatrics. 2011;128:595610 .

6. Mathews R, Mattoo TK. The role of antimicrobial prophylaxis in the management of children with vesicoureteral reflux - the RIVUR study outcomes. Adv Chronic Kidney Dis. 2015;22(4):325-30.

7. Jackson EC. Urinary tract infections in children: knowledge updates and a salute to the future. Pediatr Rev. 2015; 36(4):153-6.

8. Lebowitz RL, Olbing H, Parkkulainen KV, Smellie JM, Tamminen-Mobius TE. International system of radiographic grading of vesicoureteric reflux. International Reflux Study in Children. Pediatr Radiol. 1985; 15:105-9.

9. Perisinakis K, Raissaki M, Damilakis J, Stratakis J, Neratzoulakis J, Gourtsoyiannis N. Fluoroscopy- controlled voiding cystourethrography in infants and children: are the radiation risks trivial? Eur Radiol. 2006;16:846-51.

10. Ward VL. Patient dose reduction during voiding cystourethrography. Pediatr Radiol. 2006; 36 (Suppl 2): 168-72.

11. Ward VL, Strauss KJ, Barnewolt CE, Zurakowski D, Venkatakrishnan V, Fahey FH et al. Pediatric radiation exposure and effective dose reduction during voiding cystourethrography. Radiology.2008;249(3):1002-9.

12. Schneider K, Kruger-Stollfuss I, Ernst G, Kohn MM. Paediatric fluoroscopy-a survey of children's hospitals in Europe. I. Staffing, frequency of fluoroscopic procedures and investigation technique. Pediatr Radiol. 2001;31:238-46.

13. Papadopoulou F, Efremidis SC, Oiconomou A, Badauraki M, Panteleli M, Papachristou F, et al. Cyclic voiding cystourethrography: is vesicoureteral reflux missed with standard voiding cystourethrography? Eur Radiol. 2002;12(3):666-70.

14. Unver T, Alpay H, Biyikli NK, Ones T. Comparison of direct radionuclide cystography and voiding cystourethrography in detecting vesicoureteral reflux. Pediatr Int. 2006;48:287-91.

15. Faizah MZ, Hamzaini AH, Kanaheswari Y, Dayang A AA, Zulfigar MA. Contrast enhanced Voiding Urosonography (ce-VUS) as a radiation-free technique in the diagnosis of vesicoureteric reflux: Our early experience. Med J Malaysia. 2015;70(5):269-72.

16. Wong LS, Tse KS, Fan TW, Kwok KY, Tsang TK, Fung HS, et al. Voiding urosonography with second-generation ultrasound contrast versus micturating cystourethrography in the diagnosis of vesicoureteric reflux. Eur J Pediatr. 2014; 173(8):1095-101.

17. Papadopoulou F, Ntoulia A, Siomou E, Darge K. Contrast enhanced voiding urosonography with intravesical administration of a second-generation ultrasound contrast agent for diagnosis of vesicoureteral reflux: prospective evaluation of contrast safety in 1,010 children. Pediatr Radiol. 2014; 44(6):719-28.

18. Roić G, Cvitković Roić A, Grmoja T, Posarić V, Marijanović J, Miletić D, et al. Diagnostic imaging in the diagnosis of vesicoureteral reflux: from the beginning to the present. Paediatr Croat. 2014;58:51-8.

19. Roić G. Cvitković Roić A, Palčić I, Miletić D. Ultrasound contrast cystography with contrast enhanced software in the diagnosis of vesicoureteral reflux. Medicina Fluminens. 2014;50:188-196. 
20. Ključevšek D, Battelino N, Tomažič M, Kersnik Levart T. A comparison of echo-enhanced voiding urosonography with X-ray voiding cystourethrography in the first year of life. Acta Paediatr. 2012;101:e235-9.

21. Darge K. Diagnosis of vesicoureteral reflux with ultrasonography. Pediatr Nephrol. 2002;17:52-60.

22. Darge K. Voiding urosonography with ultrasound contrast agents for the diagnosis of vesicoureteric reflux in children. I. Procedure. Pediatr Radiol. 2008;38:40-53.

23. Papadopoulou F, Anthopoulou A, Siomou E, Efremidis S, Tsamboulas C, Darge K. Harmonic voiding urosonography with a second-generation contrast agent for the diagnosis of vesicoureteral reflux. Pediatr Radiol. 2009;39:239-44.

24. Kis E, Nyitrai A, Varkonyi I, Máttyus I, Cseprekál $\mathrm{O}$, Reusz $\mathrm{G}$, et al. Voiding urosonography with second-generation contrast agent versus voiding cystourethrography. Pediatr Nephrol. 2010;25:2289-93.

25. Novljan G, Kenig A, Rus R, Kenda RB. Cyclic voiding urosonography in detecting vesicoureteral reflux in children. Pediatr Nephrol. 2003;18:992-5.

26. Riccabona M. Contrast ultrasound of the urethra in children. Eur Radiol. 2003;13:1494-5.

27. Berrocal T, Rivas S, Jaureguizar E, Gómez-León N, Lobato R, Martínez-Urrutia MJ, et al. Contrastenhanced sonourethrography in the assessment of the urethra. Cir Pediatr. 2004;17:58-60.

28. Berrocal T, Gaya F, Arjonilla A. Vesicoureteral reflux: can the urethra be adequately assessed by using contrast-enhanced voiding US of the bladder? Radiology. 2005;234:235-41.

29. Bosio M. Role of ultrasound in the imaging of posterior urethral valves. Rays. 2002;27:135-9.

30. Kaneko K, Kuwatsuru R, Fukuda Y, Yamataka A, Yabuta K, Katayama H, et al. Contrast sonography for detection of vesicoureteral reflux. Lancet. 1994; 344:687.

31. von Rohden L, Bosse U, Wiemann D. Refluxsonographie bei Kindern mit einem Ultraschallkontrastmittel im Vergleich zur Röntgenmiktionszystourethro-graphie. Paediat Prax. 1995;49:49-58.

32. Bosio M. Cystosonography with echocontrast: a new imaging modality to detect vesicoureteric reflux in children. Pediatr Radiol. 1998;28:250-5.

33. Kenda RB, Kenig A, Novljan G, Ponikvar R, Buturović Ponikvar J. Cyclic voiding urosonography for detecting vesicoureteric reflux in renal transplant recipients. Nephrol Dial Transplant. 2001;16:2229-31.

34. Novljan G, Kenig A, Rus R, Kenda RB. Cyclic voiding urosonography in detecting vesicoureteral reflux in children. Pediatr Nephrol. 2003;18:992-5.

35. Tranquart F, Grenier N, Eder V, Pourcelot L. Clinical use of ultrasound tissue harmonic imaging. Ultrasound Med Biol. 1999;25:889-94.

36. Bosio M. Cystosonography with echocontrast: a new imaging modality to detect vesicoureteric reflux in children. Pediatr Radiol. 1998;28:250-5.

37. Schneider M. SonoVue, a new ultrasound contrast agent. Eur Radiol. 1999;9 (Suppl 3):347S-348S.

38. Papadopoulou F, Katzioti F, Arkoumani E, Siomou E, Evaggelidou E, Efremidis S. Voiding urosonography harmonic imaging with 2 nd generation contrast agent for the diagnosis of reflux. Pediatr Radiol. 2005;35:130S.

39. Papadopoulou F, Anthopoulou A, Siomou E, Efremidis S, Tsamboulas C, Darge K. Harmonic voiding urosonography with a second-generation contrast agent for the diagnosis of vesicoureteral reflux. Pediatr Radiol. 2009;39:239-44.

40. Darge K, Troeger J. Vesicoureteral reflux grading in contrast-enhanced voiding urosonography. Eur J Radiol. 2002;43:122-8.

41. Darge K. Voiding urosonography with US contrast agents for the diagnosis of vesicoureteric reflux in children. II. Comparison with radiological examinations. Pediatr Radiol. 2008;38:54-63.

42. Prasad MM, Cheng EY. Radiographic evaluation of children with febrile urinary tract infection: bottom-up, top-down, or none of the above? Adv Urol. 2012;2012:716739.

43. Riccabona M. Application of a second-generation US contrast agent in infants and children - a European questionnaire-based survey. Pediatr Radiol. 2012;42:1471-80.

44. Koff SA. Estimating bladder capacity in children. Urology. 1983;21:248.

45. Riccabona M, Avni FE, Blickman JG, Dacher JN, Darge K, Lobo ML, et al. Imaging recommendations in paediatric uroradiology: minutes of the ESPR workgroup session on urinary tract infection, fetal hydronephrosis, urinary tract ultrasonography and voiding cystourethrography, Barcelona, Spain, June 2007. Pediatr Radiol. 2008;38:138-45.

46. Duran C, Valera A, Alguersuari A, Ballesteros E, Riera L, Martin C, et al. Voiding urosonography: 
the study of the urethra is no longer a limitation of the technique. Pediatr Radiol. 2009;39:124-31.

47. Riccabona M, Avni FE, Damasio MB, OrdingMüller LS, Blickman JG, Darge K, et al. ESPR Uroradiology Task Force and ESUR Paediatric
Working Group - Imaging recommendations in paediatric uroradiology, part V: childhood cystic kidney disease, childhood renal transplantation and contrast-enhanced ultrasonography in children. Pediatr Radiol. 2012;42:1275-83. 